\title{
DATABASE AND ANALYTICAL TOOL DEVELOPMENT FOR THE MANAGEMENT OF DATA DERIVED FROM US DOE (NETL) FUNDED FINE PARTICULATE $\left(\mathrm{PM}_{2.5}\right)$ RESEARCH
}

\section{Semi-Annual Technical Progress Report}

REPORT PERIOD START DATE:

REPORT PERIOD END DATE:
August 12, 2006

February 11, 2007
PRINCIPAL AUTHORS:

DATE REPORT ISSUED:

DOE AWARD NUMBER:

CONTRACTOR:

SUBCONTRACTORS:
Robinson P. Khosah, Ph.D. Advanced Technology Systems, Inc. Frank T. Alex Advanced Technology Systems, Inc.

February 2007

DE-FC26-02NT41476

Advanced Technology Systems, Inc. 260 Airside Drive Pittsburgh, PA 15108

Ohio University E317 Grover Ohio University Athens, OH 45701

Texas A\&M University - Kingsville MSC213

Texas A\&M University - Kingsville Kingsville, TX 78363

01-050-S\&T-P

ATS PROJECT NO: 


\begin{abstract}
Advanced Technology Systems, Inc. (ATS) was contracted by the U. S. Department of Energy's National Energy Technology Laboratory (DOE-NETL) to develop a state-ofthe-art, scalable and robust web-accessible database application to manage the extensive data sets resulting from the DOE-NETL-sponsored ambient air monitoring programs in the upper Ohio River valley region. The data management system was designed to include a web-based user interface that will allow easy access to the data by the scientific community, policy- and decision-makers, and other interested stakeholders, while providing detailed information on sampling, analytical and quality control parameters. In addition, the system will provide graphical analytical tools for displaying, analyzing and interpreting the air quality data. The system will also provide multiple report generation capabilities and easy-to-understand visualization formats that can be utilized by the media and public outreach/educational institutions. The project is being conducted in two phases. Phase One includes the following tasks: (1) data inventory/benchmarking, including the establishment of an external stakeholder group; (2) development of a data management system; (3) population of the database; (4) development of a web-based data retrieval system, and (5) establishment of an internal quality assurance/quality control system on data management. Phase Two, which is currently underway, involves the development of a platform for on-line data analysis. Phase Two includes the following tasks: (1) development of a sponsor and stakeholder/user website with extensive online analytical tools; (2) development of a public website; (3) incorporation of an extensive online help system into each website; and (4) incorporation of a graphical representation (mapping) system into each website. The project is now into its forty-eighth month of development activities.
\end{abstract}

\title{
DISCLAIMER
}

This report was prepared as an account of work sponsored by an agency of the United States Government. Neither the United States Government nor any agency thereof, nor any of their employees, makes any warranty, express or implied, or assumes any legal liability or responsibility for the accuracy, completeness, or usefulness of any information, apparatus, product, or process disclosed, or represents that its use would not infringe privately owned rights. Reference herein to any specific commercial product, process, or service by trade name, trademark, manufacturer, or otherwise does not necessarily constitute or imply its endorsement, recommendation, or favoring by the United States Government or any agency thereof. The views and opinions of authors expressed herein do not necessarily state or reflect those of the United States Government or any agency thereof. 


\section{TABLE OF CONTENTS}

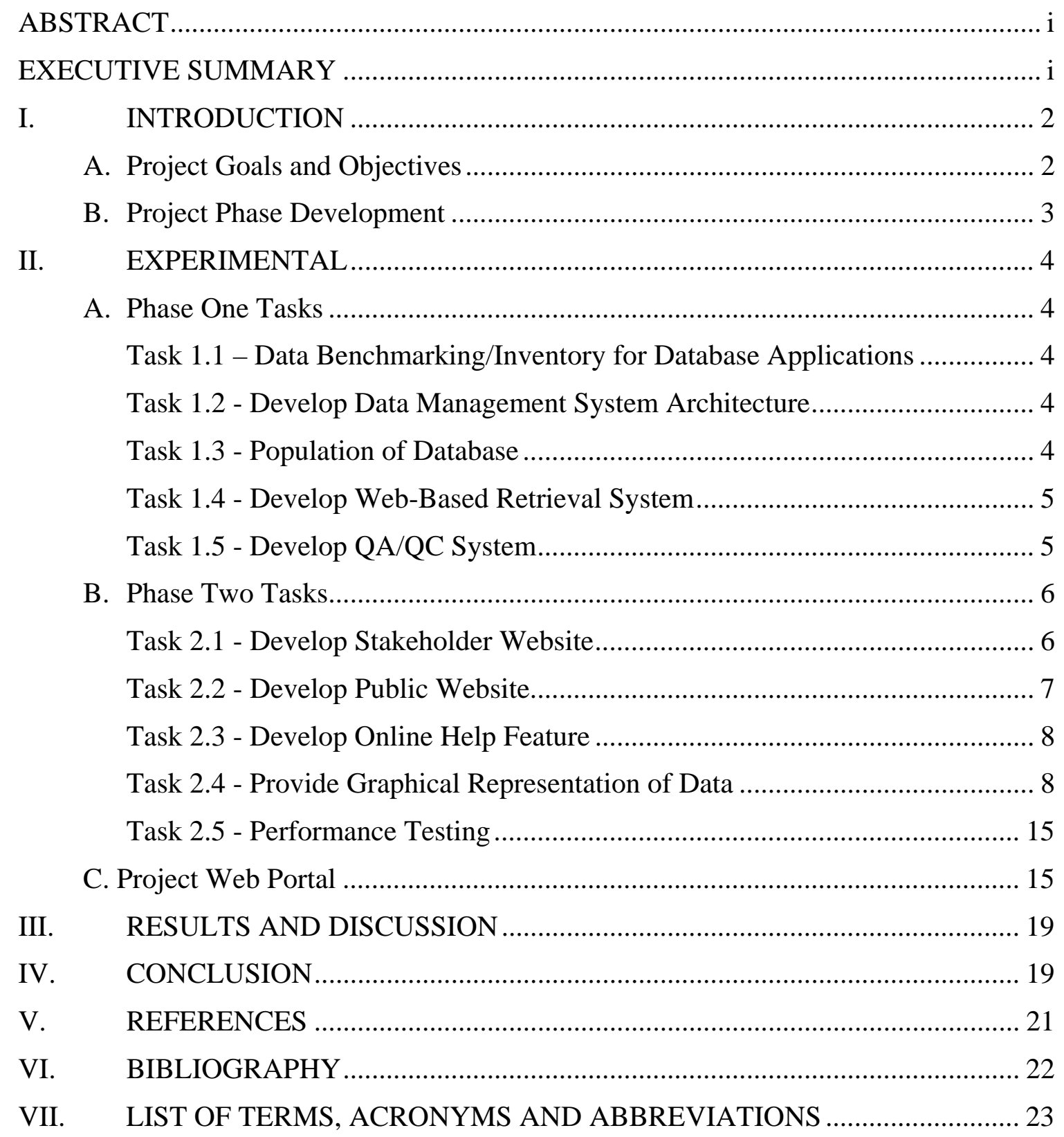




\section{LIST OF GRAPHICAL MATERIALS}

Figure 1 - Visible Changes to Stakeholder Application ................................................. 7

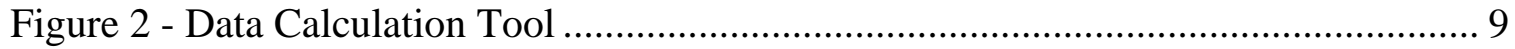

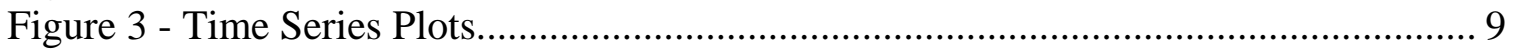

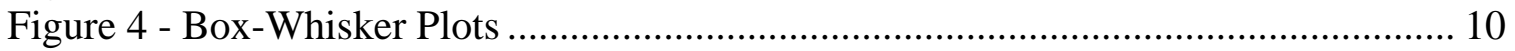

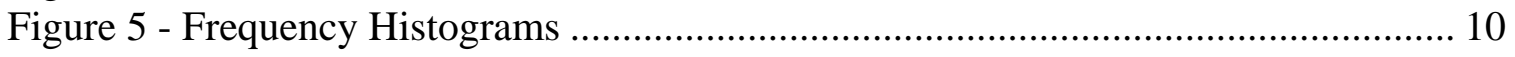

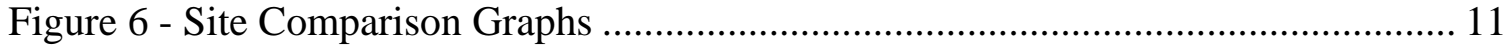

Figure 7 - Speciation Filter Composition Tool with Timeline Control ............................ 12

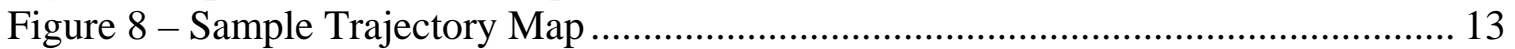

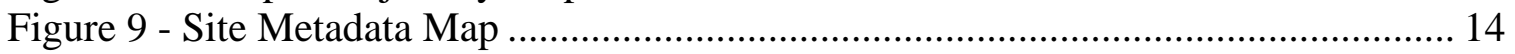

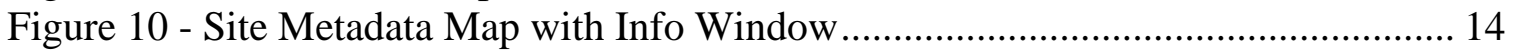

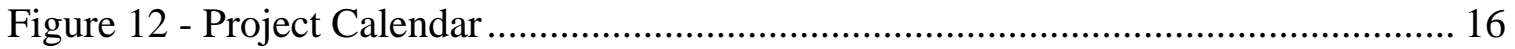

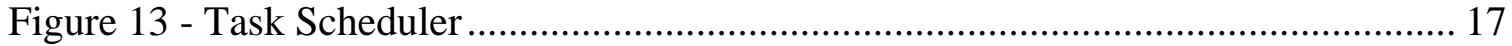

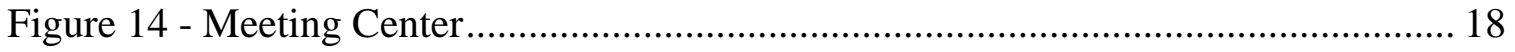

\section{LIST OF TABLES}

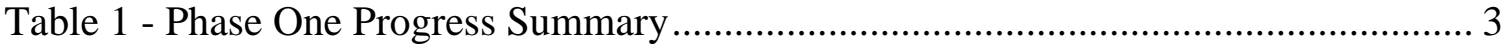

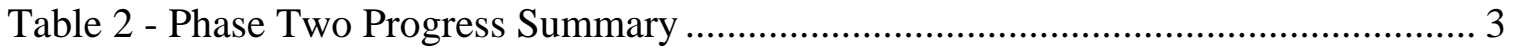

Table 3 - UORVP Data Inventory .............................................................................. 5

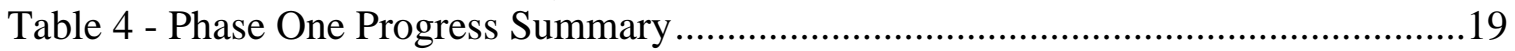

Table 5 - Phase Two Progress Summary .....................................................................19 


\section{EXECUTIVE SUMMARY}

Advanced Technology Systems, Inc. (ATS) was contracted by the U. S. Department of Energy's National Energy Technology Laboratory (DOE-NETL) in August, 2002, to develop a state-of-the-art, scalable and robust web-accessible database application to manage the extensive data sets resulting from ambient air monitoring programs in the upper Ohio River valley region that have been sponsored by DOE-NETL.

Research projects sponsored by DOE-NETL collected large amounts of data on $\mathrm{PM}_{2.5}$ and other air pollutants at ambient monitoring sites in the upper Ohio River valley region between 1999 and 2003. Extensive monitoring sites have been operated by DOE-NETL and its contractors in Pittsburgh, PA (two (2) urban sites), Holbrook, PA (rural site), South Park, PA (suburban site), and Steubenville, $\mathrm{OH}$. Less-extensive monitoring sites have been operated in six other locations in $\mathrm{PA}, \mathrm{OH}$ and WV. The main objectives of the current effort are to gather the data from all these monitoring sites into a common database, and to develop analytical tools that will make the data easily accessible to researchers and the public via the Internet.

In addition to the data collected by DOE-NETL and its contractors, the database will include, to the greatest extent possible, ambient air data collected by other agencies in the upper Ohio River valley region, such as the U.S. EPA, Pennsylvania Department of Environmental Protection (PA-DEP), West Virginia Division of Environmental Protection (WV-DEP), Ohio EPA, and the Allegheny County Health Department (ACHD). Although emphasis is being placed on the upper Ohio River valley region, the database may also include data collected at other DOE-NETL sponsored sites outside the region, such as sites operated by the Tennessee Valley Authority in the Great Smokey Mountains and by the Southern Research Institute in North Birmingham, AL. The database and analytical tool development effort is also being coordinated, to the extent possible, with a similar effort by U.S. EPA to develop a relational database for data collected at its "PM Supersites". This coordination will ensure that the database and analytical tools produced under the DOE-NETL effort will be readily accessible to a wide variety of stakeholders.

The data management system will include a web-based user interface that will allow easy access to the data by the scientific community, policy- and decision-makers, and other interested stakeholders, while providing detailed information on sampling, analytical and quality control parameters. In addition, the system will provide graphical analytical tools for displaying, analyzing and interpreting the air quality data. The system will also provide multiple report generation capabilities and easy-to-understand visualization formats that can be utilized by the media and public outreach/educational institutions.

The project is being conducted in two phases. The entire project has been divided into ten primary tasks and those have been segmented into two primary phases. The project is currently in forty-eighth month of development tasks and Phase Two began in August, 2003. Phase One consisted of design and specification tasks related to designing, implementing and populating the primary database that will house the collected data. Phase Two consists of tasks involving the design, implementation and testing of both website interfaces along with any analytical tools and features integrated into the project's websites. 


\section{INTRODUCTION}

Advanced Technology Systems, Inc. (ATS) was contracted by the U. S. Department of Energy's National Energy Technology Laboratory (DOE-NETL) in August, 2002, to develop a state-of-the-art, scalable and robust web-accessible database application to manage the extensive data sets resulting from ambient air monitoring programs in the upper Ohio River valley region that have been sponsored by DOE-NETL.

Research projects sponsored by DOE-NETL collected large amounts of data on $\mathrm{PM}_{2.5}$ and other air pollutants at ambient monitoring sites in the upper Ohio River valley region between 1999 and 2003. Extensive monitoring sites have been operated by DOE-NETL and its contractors in Pittsburgh, PA (two (2) urban sites), Holbrook, PA (rural site), South Park, PA (suburban site), and Steubenville, OH. Less-extensive monitoring sites have been operated in six other locations in $\mathrm{PA}, \mathrm{OH}$ and $\mathrm{WV}$. The main objectives of the current effort are to gather the data from all these monitoring sites into a common database, and to develop analytical tools that will make the data easily accessible to researchers and the public via the Internet.

In addition to the data collected by DOE-NETL and its contractors, the database will include, to the greatest extent possible, ambient air data collected by other agencies in the upper Ohio River valley region, such as the U.S. EPA, Pennsylvania Department of Environmental Protection (PA-DEP), West Virginia Division of Environmental Protection (WV-DEP), Ohio EPA, and the Allegheny County Health Department (ACHD). Although emphasis is being placed on the upper Ohio River valley region, the database may also include data collected at other DOE-NETL sponsored sites outside the region, such as sites operated by the Tennessee Valley Authority in the Great Smokey Mountains and by the Southern Research Institute in North Birmingham, AL. The database and analytical tool development effort is also being coordinated, to the extent possible, with a similar effort by U.S. EPA to develop a relational database for data collected at its "PM Supersites". This coordination will ensure that the database and analytical tools produced under the DOE-NETL effort will be readily accessible to a wide variety of stakeholders.

The data management system will include a web-based user interface that will allow easy access to the data by the scientific community, policy- and decision-makers, and other interested stakeholders, while providing detailed information on sampling, analytical and quality control parameters. In addition, the system will provide graphical analytical tools for displaying, analyzing and interpreting the air quality data. The system will also provide multiple report generation capabilities and easy-to-understand visualization formats that can be utilized by the media and public outreach/educational institutions.

The project is being conducted in two phases. The project is now into its forty-eighth month of development activities.

\section{A. Project Goals and Objectives}

The main objective of this database development effort is to gather the data, acquired from all these monitoring sites, into a common database, and develop analytical tools that will make the data easily accessible to researchers and the public via the Internet. 
The proposed data management system will include a web-based user interface that will allow easy access to the data by the scientific community, policy- and decision-makers, and other interested stakeholders, while providing detailed information on sampling, analytical and quality control parameters. In addition, the system will provide graphical analytical tools for displaying, analyzing and interpreting the air quality data. The system will also provide multiple report generation capabilities and easy-to-understand visualization formats that can be utilized by the media and public outreach/educational institutions.

\section{B. Project Phase Development}

The project is being conducted in two phases. The first phase includes data inventory, benchmarking and database population tasks, as well as the development of data management architecture, a web-based retrieval system and an internal QA/QC system. A progress summary for Phase One is shown in Table 1.

Table 1 - Phase One Progress Summary

\begin{tabular}{|l|l|l|l|}
\hline Task \# & Description & $\begin{array}{l}\text { Planned } \\
\text { completed }\end{array}$ & $\begin{array}{l}\text { Actual \% } \\
\text { completed }\end{array}$ \\
\hline 1.1 & Data Inventory/Benchmarking for Database Applications & $100 \%$ & $100 \%$ \\
\hline 1.2 & Develop Data Management System Architecture & $100 \%$ & $100 \%$ \\
\hline 1.3 & Population of Database & $100 \%$ & $100 \%$ \\
\hline 1.4 & Develop Web-based Retrieval System & $100 \%$ & $100 \%$ \\
\hline 1.5 & Develop Internal QA/QC System & N/A & N/A \\
\hline
\end{tabular}

The second project development phase is currently being finalized. The tasks involved in this phase include the development of a stakeholder-specific website, a publicly accessible website and an online help feature. This phase also includes the development of special analysis tools to provide a graphical representation of the data and a series of performance tests designed to provide the best possible data management solution.

A progress summary for Phase Two is shown in Table 2.

Table 2 - Phase Two Progress Summary

\begin{tabular}{|l|l|l|l|}
\hline Task \# & Description & $\begin{array}{l}\text { Planned } \\
\text { completed }\end{array}$ & $\begin{array}{l}\text { Actual } \\
\text { completed }\end{array}$ \\
\hline 2.1 & Develop Stakeholder Website & $100 \%$ & $100 \%$ \\
\hline 2.2 & Develop Public Website & $100 \%$ & $99 \%$ \\
\hline 2.3 & Develop Online Help Feature & $100 \%$ & $90 \%$ \\
\hline 2.4 & Provide Graphical Representation of Data & $100 \%$ & $100 \%$ \\
\hline 2.5 & Performance Test & $100 \%$ & $75 \%$ \\
\hline
\end{tabular}




\section{EXPERIMENTAL}

\section{A. Phase One Tasks}

\section{Task 1.1 - Data Benchmarking/Inventory for Database Applications}

Any database application development effort requires some knowledge of the types and number of data contained in the resulting database. In addition to knowing this information, it is also wise to investigate or benchmark existing applications and development efforts that are similar in design or nature as the application being developed. Therefore, ATS proposed to conduct benchmarking investigations of existing projects, activities and applications prior to embarking on this project, as well as evaluate and quantify the data destined for usage with this application.

Several items were described in detail within the first, second and third Semi-Annual Technical Reports for this project. Those included the CARB Data Management Project in California and the EPA Supersite Database Development Project.

\section{Task 1.2 - Develop Data Management System Architecture}

The first semi-annual technical report contains detailed information regarding the design of the data management system architecture. To summarize, a system has been developed using MS SQL Server 2000 Enterprise Edition, MS Windows 2000 Advanced Server and external hardware, to provide the data management system architecture for this project.

A series of database objects and scripts have been constructed to ease all software development tasks and to accommodate expansion of the system to accommodate more users and data. The second semi-annual technical report contains detailed descriptions of stored procedures, or static queries that are stored within the database structure.

Additional changes to the Data Management System Architecture have been made to accommodate additional features such as our Geographic Information Systems (GIS) site selection tools and to improve the overall performance of the data structure.

The Data Management System Architecture design is complete and has been implemented for this project. Additions and changes to stored procedures are made as required, but these changes do not significantly impact the overall design and function of this architecture.

\section{Task 1.3 - Population of Database}

As stated in previous reports, data has already been populated by using a series of conversion scripts and data processing utilities to pre-process, or re-format the supplied data source files into application-specific formats, and a special application, the PM Data Imports Utility, was developed and used to create specialized data mappings and import a large amount of data received from Desert Research Institute (DRI). These specialized data mappings involve the mapping of DRI parameters to NARSTO parameters and sometimes involve creating new parameter records for items such as 'Strong Acidity' which equates an acidity level equivalent to levels of $\mathrm{H}_{2} \mathrm{SO}_{4}$, or Sulfuric Acid. 
The project team has also imported all compatible data collected through the Pittsburgh Air Quality Study (PAQS), provided by researchers at Carnegie Mellon University (CMU). This data included a total of sixty-six (66) source files, containing data for ninety-seven (97) different parameters, for a total of one million, three hundred and sixteen thousand, eight hundred and ninety-four $(1,316,894)$ new data records. All of the PAQS observation records, with the exception of the Single Particle data, have been imported into the project database.

Table 3 - UORVP Data Inventory details the quantity of data records obtained for each collection site within the UORVP data collection network.

\begin{tabular}{|l|r|}
\hline Data Collection Site & Record Count \\
\hline PITTSBURGH SUPERSITE & $1,306,134$ \\
\hline LAWRENCEVILLE PRIMARY & 258,641 \\
\hline HOLBROOK PRIMARY & 134,066 \\
\hline MORGANTOWN SATELITE & 576 \\
\hline
\end{tabular}

Table 3 - UORVP Data Inventory

TEOM data and data obtained from the Environmental Protection Agency (EPA) for data collection sites in Pennsylvania, Ohio, West Virginia and Kentucky have also been imported into the database. For these datasets, the project team utilized Data Transformation Services (DTS) scripts to automate the population of the database and accommodate the inclusion of additional datasets in the same format.

There is one remaining primary dataset not present in the database at this time. This is data collected by the Steubenville Comprehensive Air Monitoring Program (SCAMP) sites, which has not yet been received by the project team. Appendix I - Comprehensive Data Record Inventory contains a complete listing of all data records currently in the master database.

\section{Task 1.4 - Develop Web-Based Retrieval System}

Once the data is transferred to the database, users specify which data is to be retrieved through the Query Builder Interface. This interface provides resulting datasets in a tabular format and saves the query parameters for retrieval by the analysis tools. Static datasets are also provided via HTTP protocol and users complete a criteria selection process to download the original data files. Previous Semi-Annual Technical Reports have detailed both the static data downloads controls and the dynamic query systems. In the past six months, development efforts have primarily been focused on extending and improving the existing web-based data retrieval controls, discussed in detail in previous reports.

\section{Task 1.5 - Develop QA/QC System}

The Quality Assurance/Quality Control (QA/QC) standards and processes established for this application provide for multiple layers of quality control. It is important to remember that the standards and processes mentioned in this document do not examine the quality of the data submitted, but rather ensure that the data entering the database is the same data provided by the submitting authority. Previous semi-annual technical reports detail 
the automation techniques used to verify data integrity during the database population processes.

In addition to verifying the data, the internal QA/QC system also allows for testing the website's integrity and functionality. Part of this scrutiny has resulted in the fixing of erroneous contact information and data inventory errors on the website.

The QA/QC process is an on-going exercise.

\section{B. Phase Two Tasks}

\section{Task 2.1 - Develop Stakeholder Website}

As proposed by $\boldsymbol{A T S}$, each stakeholder will have access to the entire data analysis package while the general public will have access to selected features through the public website described in Task 2.2. The stakeholder website will provide the ability to view and develop graphical representation of the digital data online for reports and for data analysis. The data analysis package will be an interactive toolset that will be embedded in the data warehouse and repository. The querying of the data permits user-defined access and review of the data. Built-in online analytical tools for advanced data analysis have been provided with the following options:

- Dynamic/interactive charting capabilities - online graphing of the data in userdefined formats

- Trend analysis - time series of pollutant data - by species, monitor and region

- Statistical analysis of pollutant profiles and distributions

- Back trajectory analysis

- Speciation filter composition analysis

Development efforts are also underway to test and potentially add the following options to this list:

- Online point source modeling capabilities

- Multi dimensional plotting capabilities (three dimensions in space (x, y, z), and time)

- Meteorological evaluations (influence on air pollutant concentrations)

- Back trajectory analysis using interactive mapping tools from Google

The stakeholder website is being developed using Microsoft Visual Studio .NET, in conjunction with Microsoft Internet Information Services (IIS), Microsoft SQL Server 2000 and the .NET framework (a packaged addition for MS Windows 2000 or XP). The project team decided to utilize the .NET framework early in the planning stages of this project because of the extensive tool sets available for this platform and the tight integration of XML Web Services into the product. XML Web Services allow remote users to retrieve datasets locally, combine multiple data sources into a single dataset and exchange data with other datasets that may, or may not, be directly related to the $\mathrm{PM}_{2.5}$ data.

As part of the development process, the project team continues to engage stakeholders to provide critical feedback so the development team can create meaningful and useful analysis tools. As stated in previous reports, a series of web casts have been conducted, 
with more planned for the near future, and the capabilities and potential for this webbased application are presented and discussed at these forums.

Additionally, the project team has also taken the project on-the-road and made presentations about the project, including live demonstrations, to researchers attending several relevant conferences and seminars. The latest conference attended by the project team members was the NOAA-EPA Golden Jubilee conference held in Raleigh, North Carolina from September 19, through September 21, 2005. The project team continues to spread awareness of the project and to solicit input for improvements to both the data retrieval and data analysis tools.

During this reporting period, the project team has redesigned the overall look and feel of the stakeholder website using updated graphics and a new and easier to use site development template. The project team will be able to build new sections of the site in a more streamlined and efficient manner as a result of this work. Figure 1 - Visible Changes to Stakeholder Application outlines the visible changes to the application.

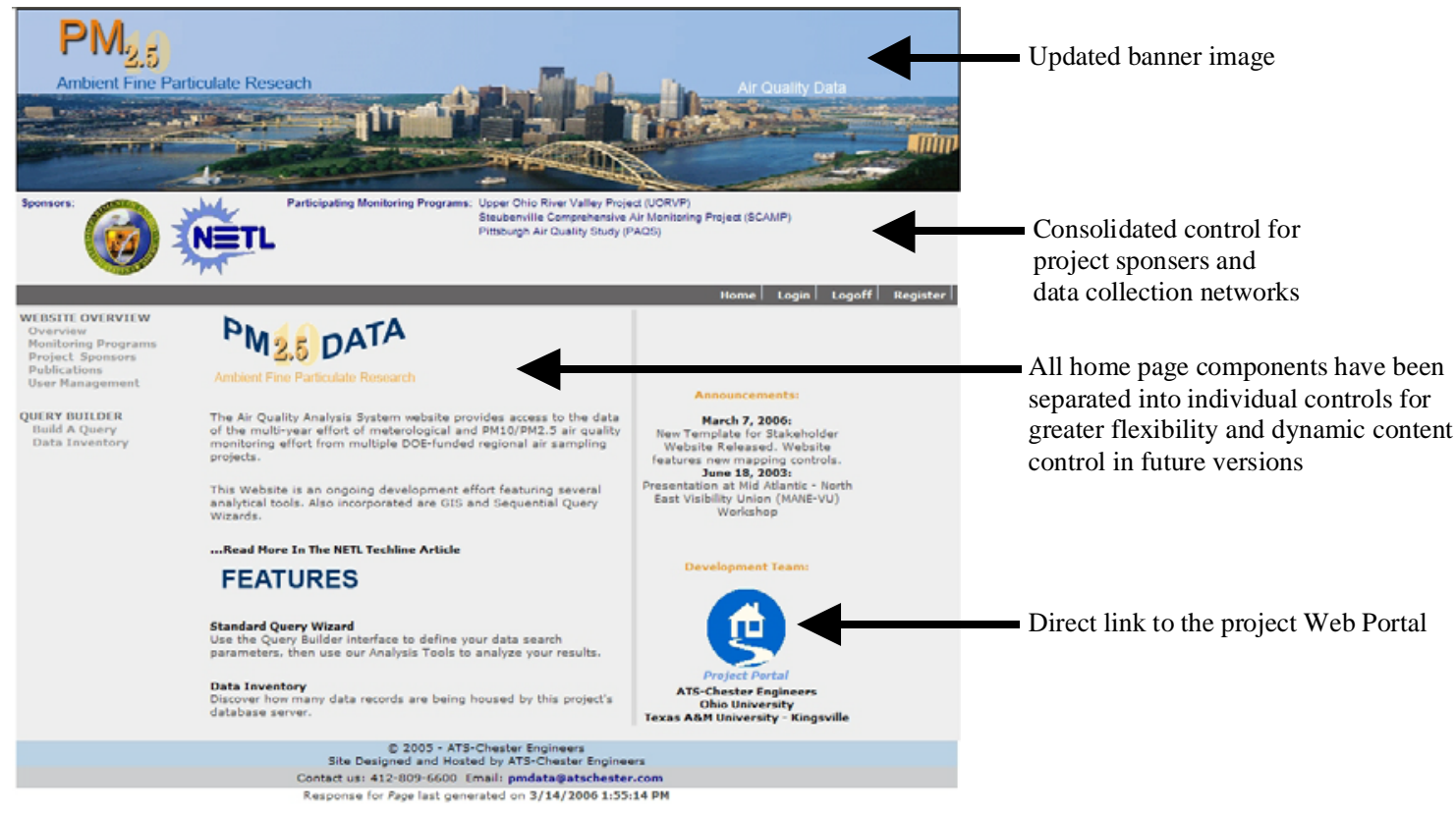

Figure 1 - Visible Changes to Stakeholder Application

\section{Task 2.2 - Develop Public Website}

ATS proposed to construct a separate website connected to the data archive for public outreach, providing the citizens of the upper Ohio River valley and at-large, along with legislative and regulatory authorities, a resource and an educational tool highlighting the extensive monitoring programs undertaken by NETL. Publicly accessible sections of the database application's web space will be available to everyone without log in. This portal will be different from the one for stakeholders, sponsors and developers, which will require registered users to submit a username and password combination before access to the restricted website is granted.

This interactive web-based application will be the backbone of the public outreach system. The web delivery system will be designed as an information/decision support center and an educational tool. The system will provide clear and concise data summaries 
from the monitoring programs and will include easy-to-understand graphical representation of the data including spatial and temporal mapping of the data accompanied by the online help as described in Task 2.3. To insure that the website will deliver information in a clear and concise manner, the deliverables of this task will be reviewed continuously by environmental and community representatives from the region prior to launching.

To date, we have developed a preliminary version of the public website which was used by DOE-NETL to advertise data availability and included a data retrieval tool to download the original data files associated with this project.

\section{Task 2.3 - Develop Online Help Feature}

ATS proposed to construct an online help feature, in conjunction with the web-based application, and it will be developed to support both the sponsor/stakeholder and the public sections website. The online help and instruction component of the application will be an interactive system that will give depth, understanding and context to the environmental data presented. The online help will assist the user at any level of scientific background (novice to professional) in the interpretation of the data. The online help will provide assistance on the following general topics:

- Definitions that will provide clear explanations of the terminology used in evaluating air pollutants

- Explanation of the Federal and State Regulations pertaining to criteria pollutants

- Background information on atmospheric chemistry, transport and emissions of air pollutants

- Effects of meteorology on air pollution episodes

- Significance of the data as it relates to public health

- Information on community-based efforts that can impact ambient air pollution levels

- Navigation of the website itself

\section{Task 2.4 - Provide Graphical Representation of Data}

The graphing and analysis tools for this project have been developed with ChartFX for .NET graphing and charting controls using the C\# .NET Web Forms environment.

ChartFX for .NET graphing and charting controls generate all the graphs on the server and generate downloadable image files from a cached dataset on the MS SQL server.

Previous reports detailed several analysis tools used to graphically represent selected datasets:

1. data calculation tool, shown in Figure 2

2. time series plots, shown in Figure 3

3. box-whisker plots, shown in Figure 4

4. frequency histograms, shown in Figure 5

5. site comparison graphs using scatter plots, shown in Figure 6

6. filter composition tool, shown in Figure 7 
Select Site

Lawrenceville Primary $\vee$

Select Parameter

PM2.5 Filter-Mass [Filter+denuder] - Duration:24 hour $\vee$

Calculation Type

1-hr Max 8 -hr Average 24 -hr Average $O$ Monthly Average

Figure 2 - Data Calculation Tool

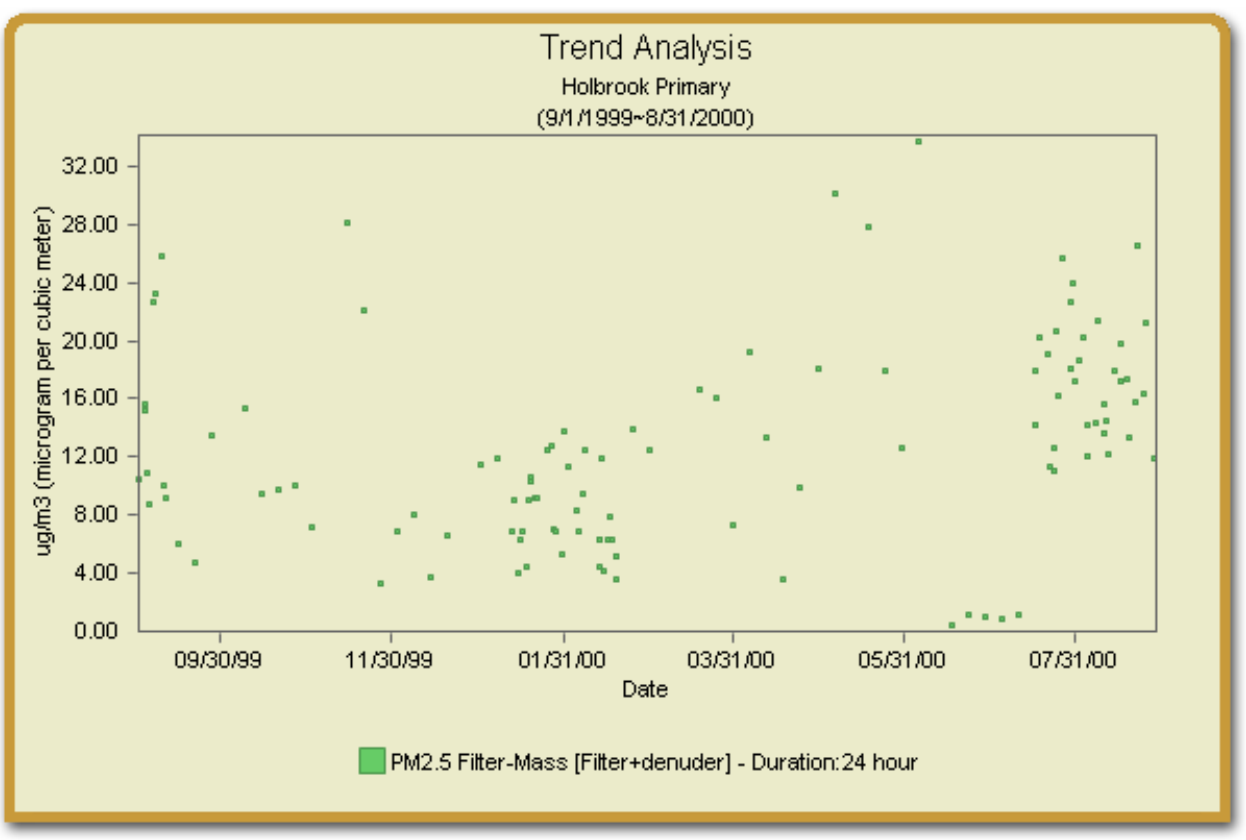

Figure 3 - Time Series Plots 


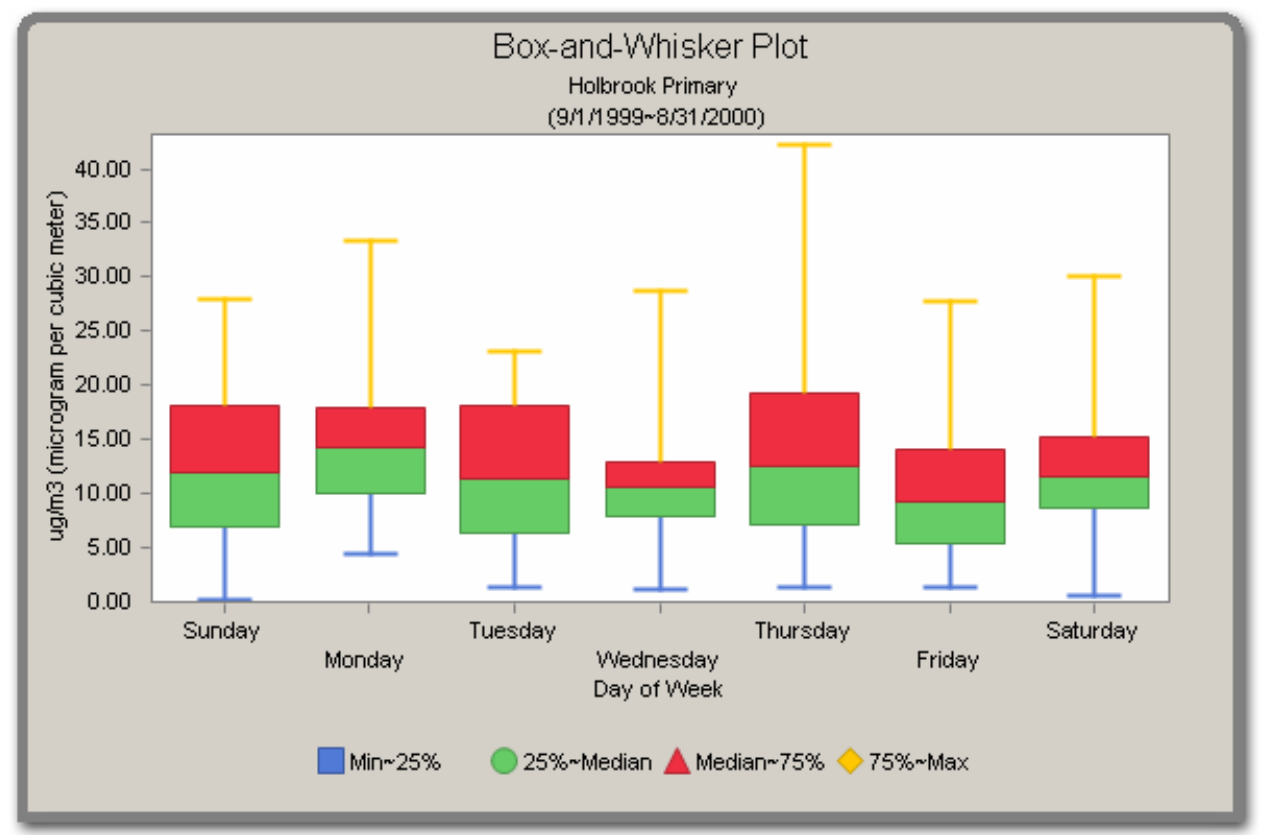

Figure 4 - Box-Whisker Plots

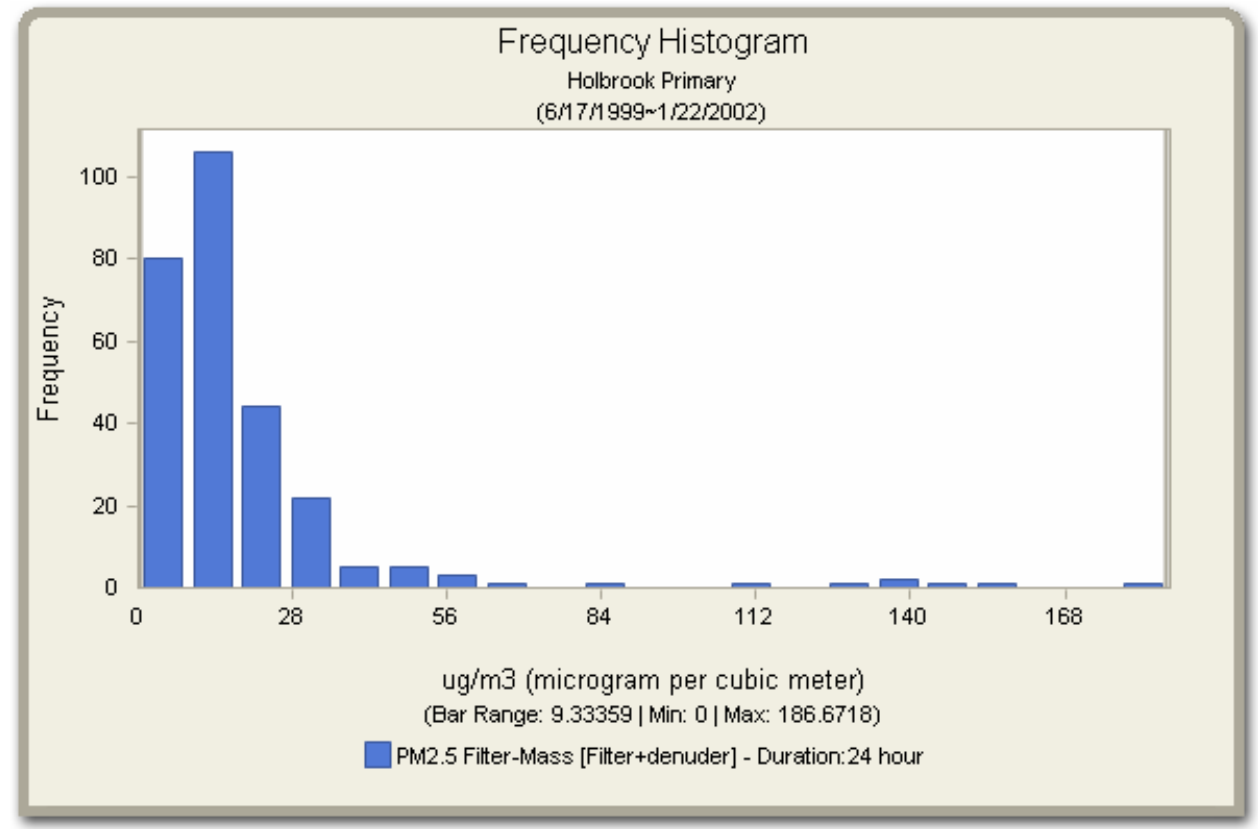

Figure 5 - Frequency Histograms 


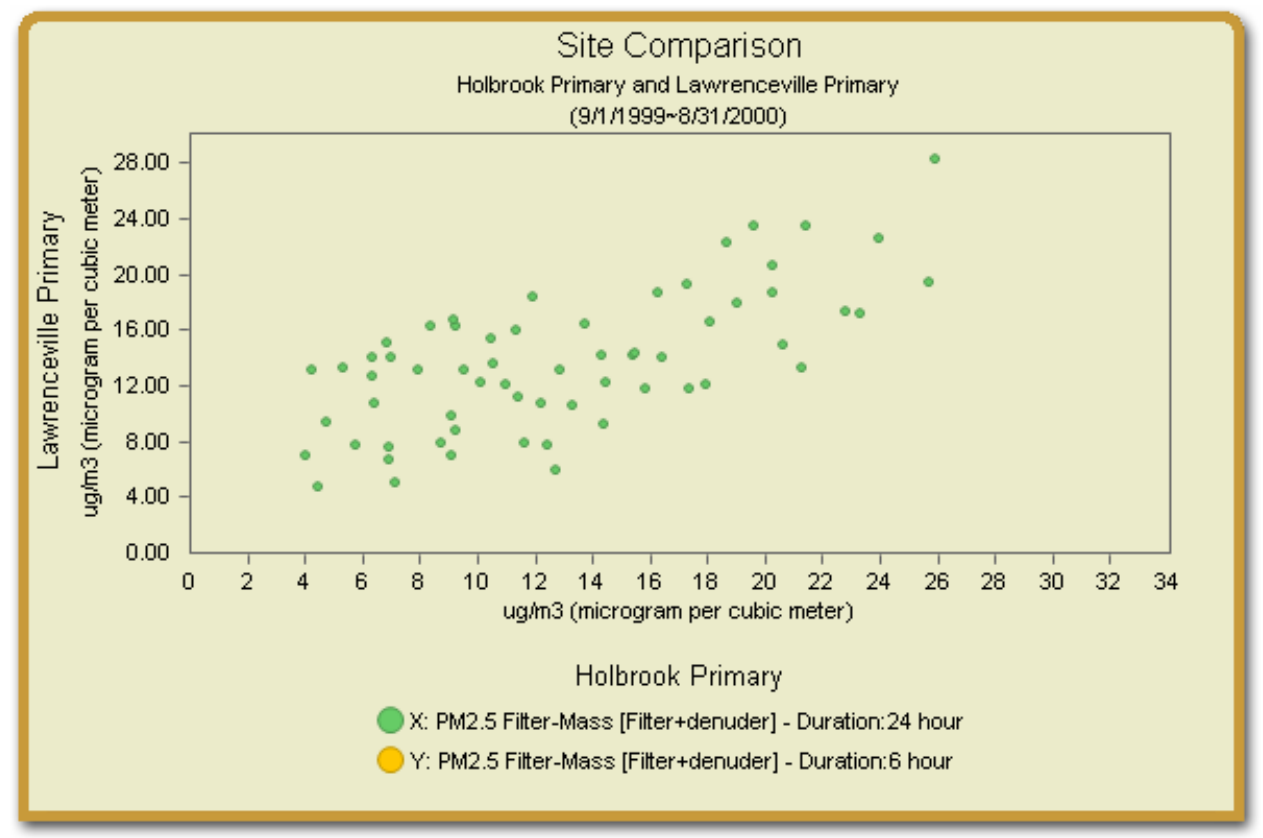

Figure 6 - Site Comparison Graphs 

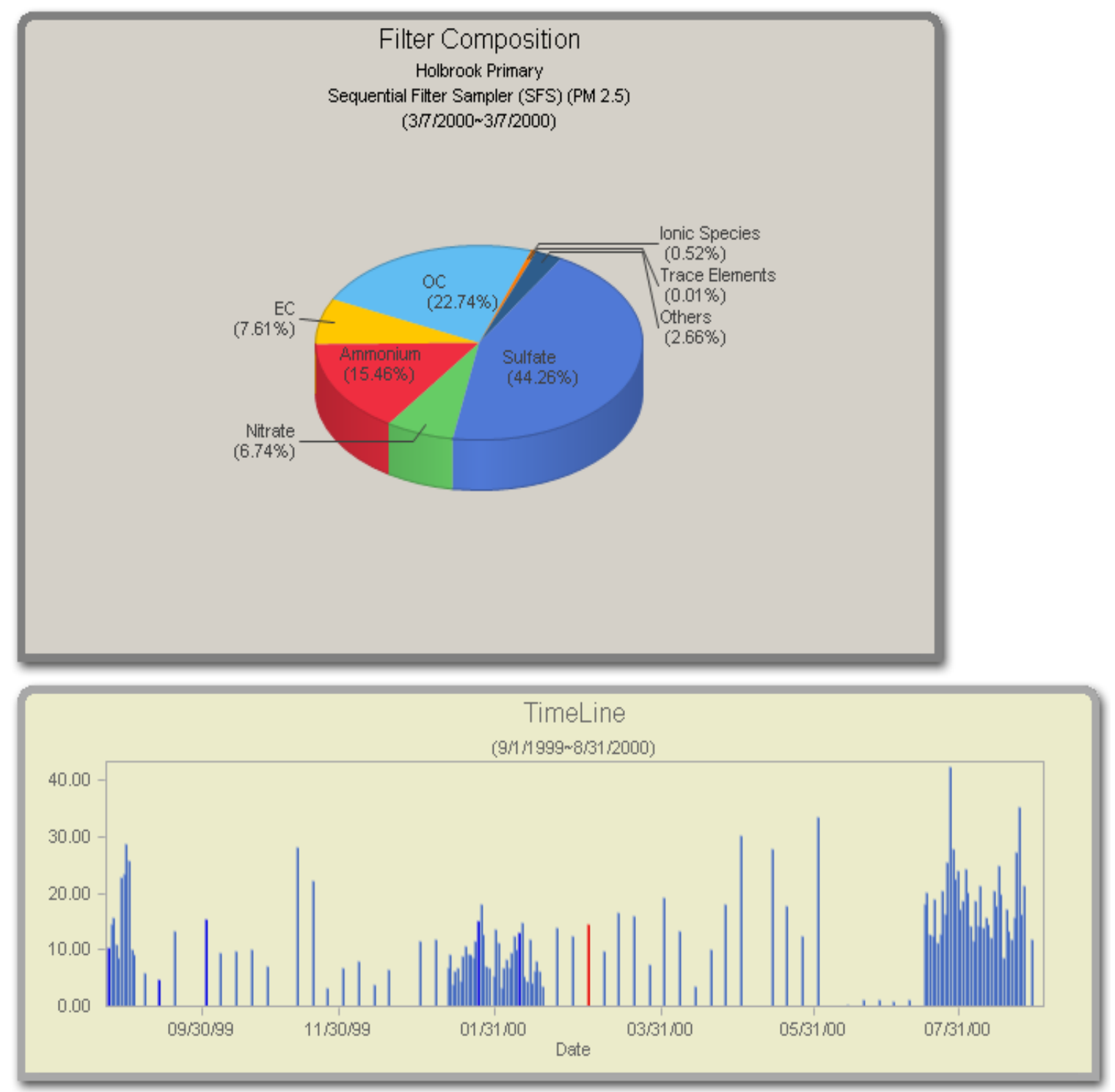

Date: $9 / 1 / 1999 m 8 / 31 / 2000$

Instrument Name: Sequential Filter Sampler (SFS) (PM 2.5) (6)

Site Name: Holbrook Primary (0)

Figure 7 - Speciation Filter Composition Tool with Timeline Control

Work continues to improve the trajectory and cluster analysis tools, shown in Figures 7 and 9 and mentioned in previous reports. These tools require the use of pre-compiled trajectory data for each data collection site. The query operations used to develop a userrequested trajectory or cluster analysis have been redesigned to accommodate more users and more frequent usage and the Java-based map used in previous versions of the application with a new interactive Google Maps control. 


\section{Trajectory Analysis}

\section{Controls}

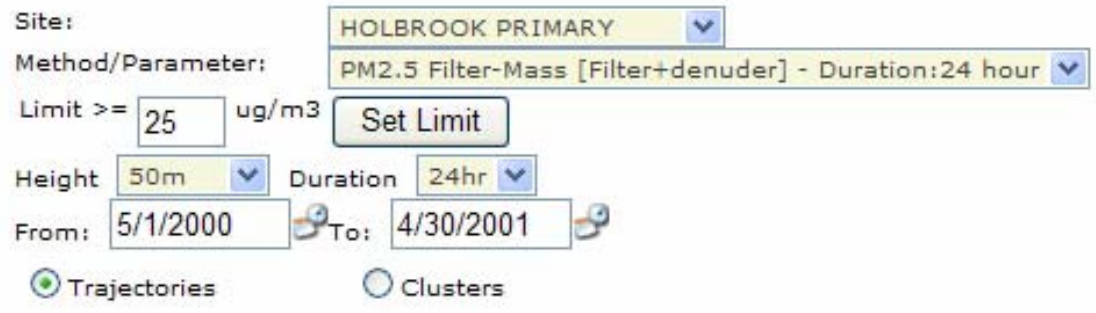

\section{Area Map}

Center Point-80.6025, 39.318

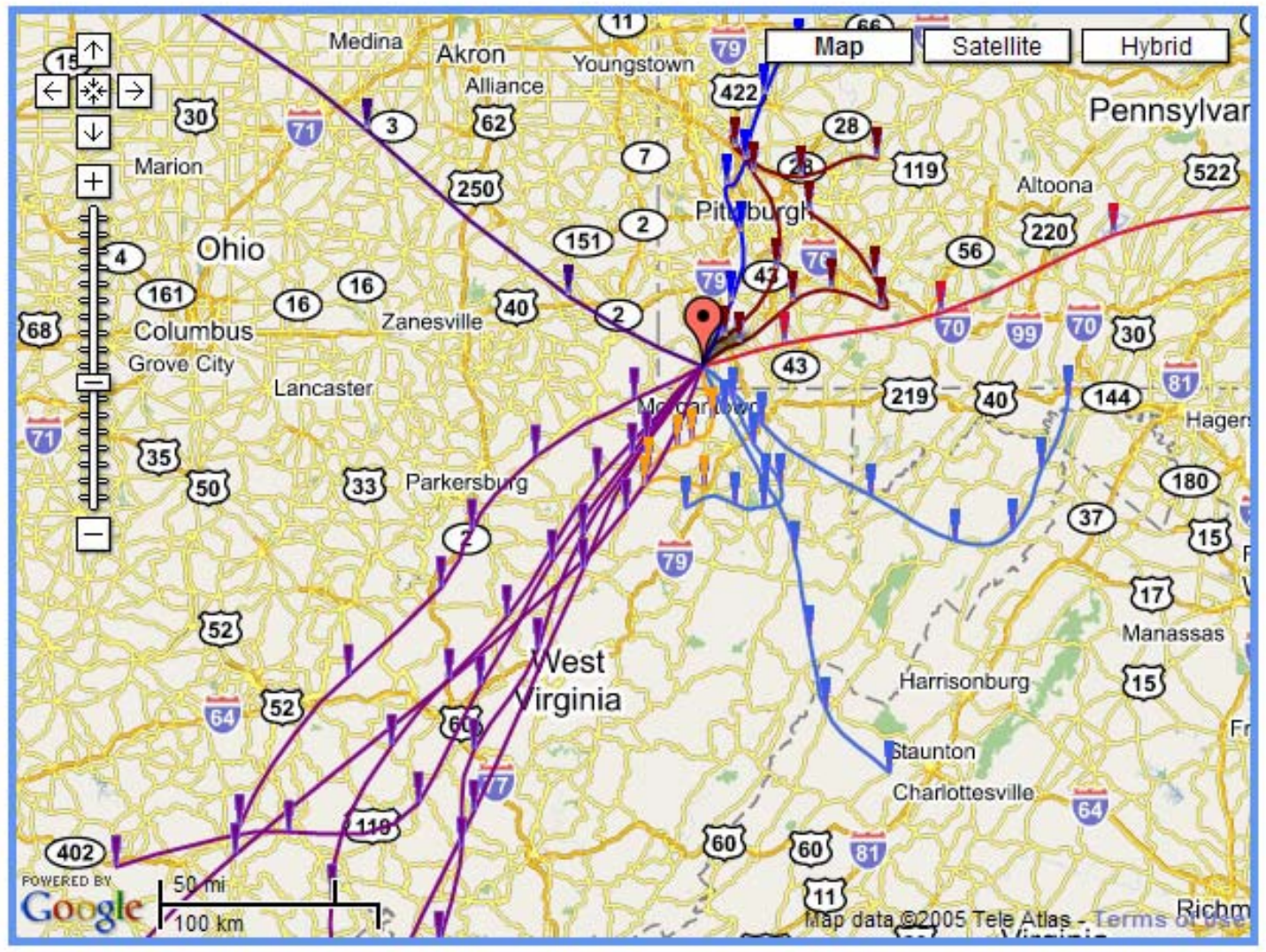

Figure 8 - Sample Trajectory Map

Our project team has also added more graphical tools to the stakeholder website such as the interactive map with data collection site metadata browser using a Google Maps interface. 


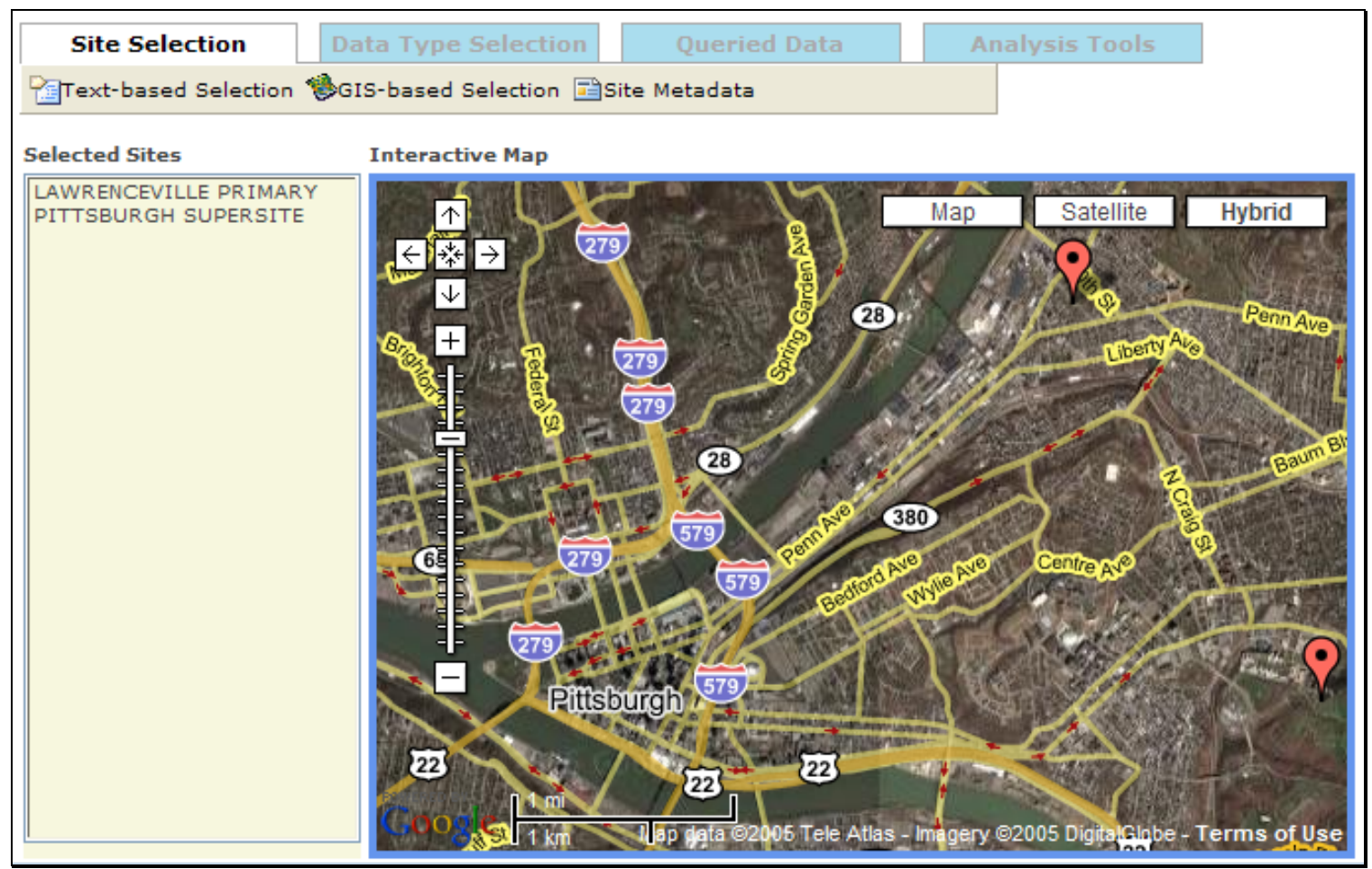

Figure 9 - Site Metadata Map

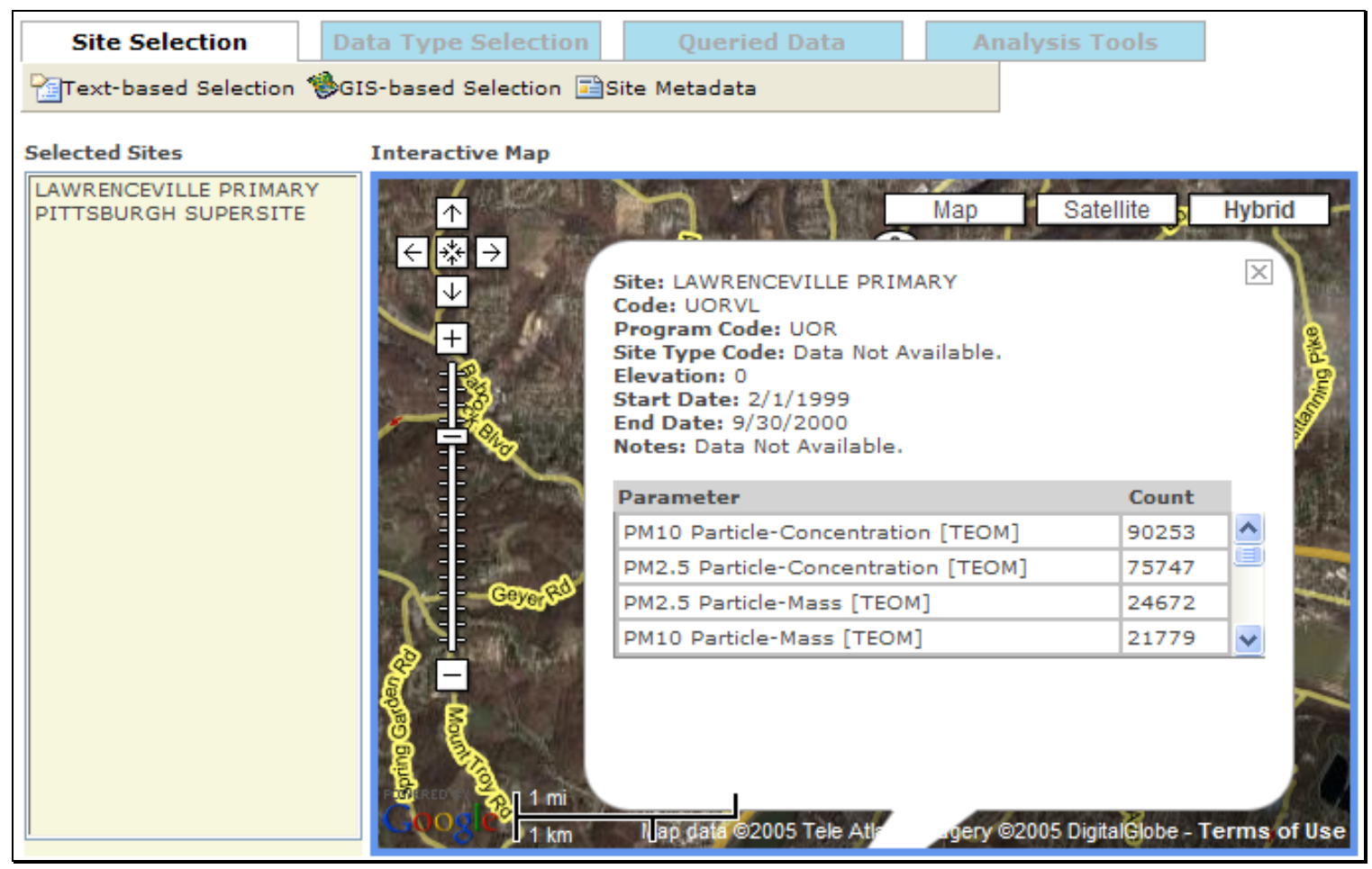

Figure 10 - Site Metadata Map with Info Window 
Future efforts will continue to improve on the tools developed thus far and the project team is also working on new tools such as an improved trajectory and cluster analysis tool, depicted in Figure 7 - Sample Trajectory Map, which will use mapping overlays to depict trajectory and cluster vector graphics on an interactive Google Maps control.

\section{Task 2.5 - Performance Testing}

ATS, in coordination with all members of the external stakeholder group, will conduct a detailed testing program for the resulting application to verify the functionality and proper execution of all portions of this application. This testing program will provide for interactive user feedback, discussion forums and periodic email notifications and announcements. This testing program will help insure that the intended objectives of this project are met or exceeded. This effort requires revisiting and reworking some of the original designs, and consequently, will be an ongoing exercise in Phase Two of this project.

Web cast participants are being asked to participate in the beta-testing phases of development and links to the applications have been provided to researchers upon request. A Project Web Portal has been implemented to facilitate this information exchange between team members and beta testers of the applications.

\section{Project Web Portal}

ATS-Chester Engineers has provided the project team with a Project Web Portal to provide the team members, client and stakeholders with a set of tools for monitoring the project tasks and for transferring files and data between registered portal users. The portal also provides the client with direct access to the team members, project discussions and status updates.

The Project Web Portal facilitates and fosters better teamwork, communication and collaboration, and file/data sharing; all of which provide DOE-NETL with a better set of products and services.

Some of the key features of the portal include a project calendar, shown in Figure 12 - Project Calendar, for scheduling important project-related events; a task scheduler, shown in Figure 13 - Task Scheduler, for monitoring project tasks and schedules; a meeting center, shown in Figure 14 - Meeting Center, to track Action Items and meeting minutes; file and data exchange tools, including an FTP link to allow for file transfers greater than $4 \mathrm{MB}$ in size; a project mapping utility for use in testing new

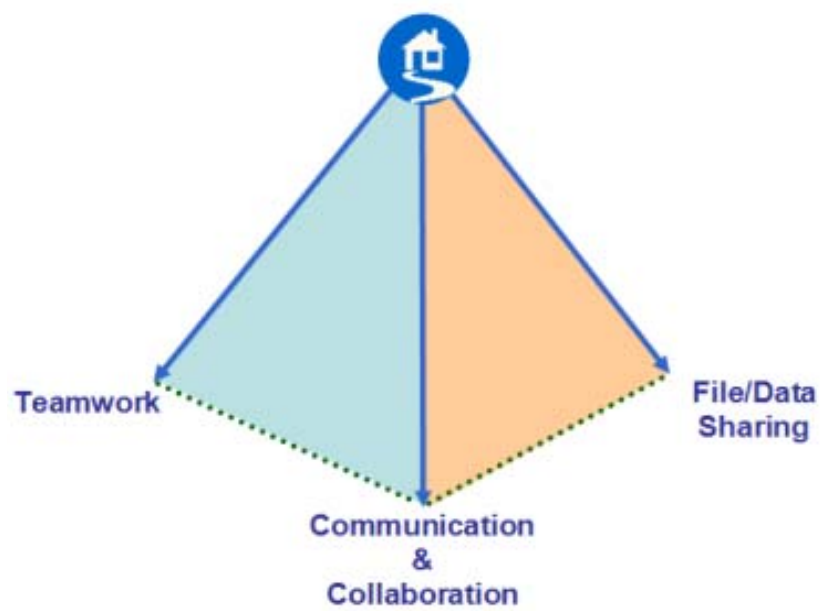

Figure 11 - Project Web Portal Cornerstones mapping controls before they are integrated into the project web sites; as well as 
miscellaneous modules such as a contacts list, project team members pictures with project role descriptions and a hyperlinks module used as a bookmarks listing for projectrelated web links.

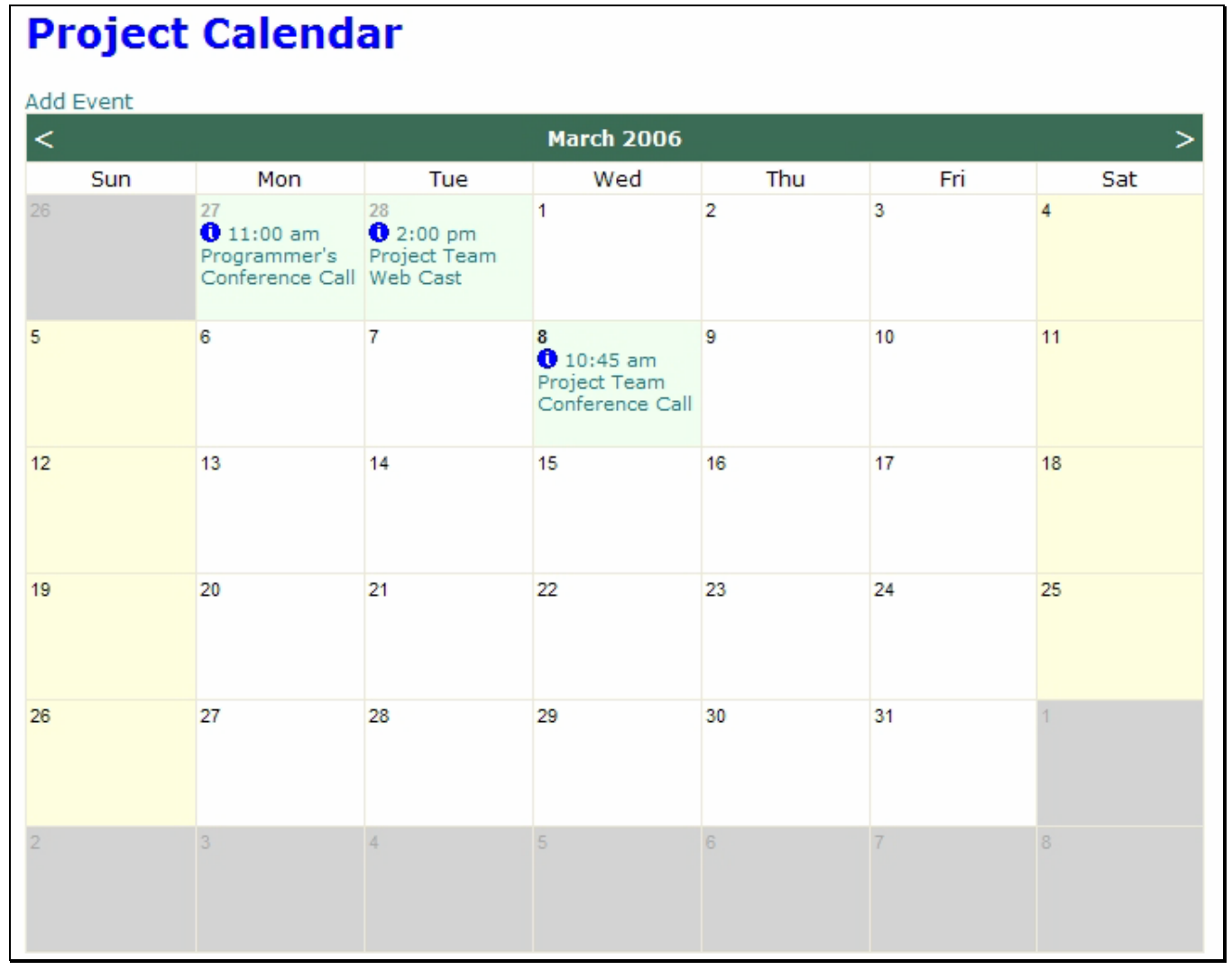

Figure 12 - Project Calendar 


\section{Project Tasks}

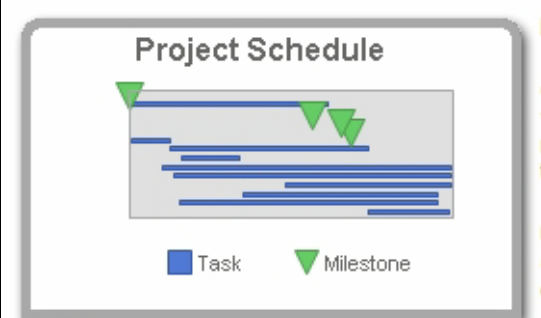

Project tasks are organized by Task Number.

Clicking on the Task Number or Status values opens the Task Editor window if your login credentials permit Task edits. Clicking on the miniature Gantt chart opens a full-sized Gantt chart with accompaning

task and milestone tables.

Users can add new tasks by clicking on the New Task button, or delete existing tasks by clicking on the trashcan icon in the far left column of the corresponding row in the task table.

\begin{tabular}{|c|c|c|c|c|c|c|}
\hline & \begin{tabular}{|l|} 
Task \\
No.
\end{tabular} & Title & \begin{tabular}{|c|} 
Duration \\
(Days)
\end{tabular} & Start Date & Target Date & Status \\
\hline 17 & Os & Project Kickoff Meeting & 1 & $09-25-2002$ & $09-25-2002$ & Complete \\
\hline 10 & 1.1 & Data Inventory and Benchmarking & 617 & $10-01-2002$ & 02-11-2005 & Complete \\
\hline 0 & $1.1 \mathrm{a}$ & $\begin{array}{l}2004 \text { Ohio Air Quality and Coal Research } \\
\text { Symposium Presentation }\end{array}$ & 2 & $12-02-2004$ & $12-06-2004$ & Complete \\
\hline 0 & $1.1 \mathrm{~b}$ & CREST-RESSACA Conference -San Antonio, TX & 4 & $04-12-2005$ & $04-15-2005$ & Complete \\
\hline 10 & $1.1 \mathrm{c}$ & IAGLR Conference 2005 & 5 & $05-23-2005$ & $05-27-2005$ & Complete \\
\hline 17 & 1.2 & Develop Data Management System Architecture & 121 & $10-01-2002$ & $03-18-2003$ & Complete \\
\hline U & 1.3 & Population of Database & 622 & $03-19-2003$ & 08-11-2005 & Complete \\
\hline U & 1.4 & Develop Web-based Retrieval System & 181 & $05-12-2003$ & 01-19-2004 & Complete \\
\hline 17 & 1.5 & Develop Internal QA/QC System & 901 & $02-17-2003$ & $08-11-2006$ & Open \\
\hline U & 2.1 & Develop Stakeholder Website & 866 & $04-07-2003$ & $08-11-2006$ & Open \\
\hline D? & 2.2 & Develop Public Website & 513 & $08-12-2004$ & $08-11-2006$ & Open \\
\hline D & 2.3 & Develop Online Help Feature & 605 & 02-09-2004 & $06-15-2006$ & Open \\
\hline U & 2.4 & Provide Graphical Representation of Data & 807 & 05-01-2003 & $06-15-2006$ & Open \\
\hline ט? & 2.5 & Performance Test & 250 & $08-11-2005$ & 08-01-2006 & Open \\
\hline
\end{tabular}

Figure 13 - Task Scheduler 


\section{Meeting Center}

\section{Action Items}

Open and Pending Action Items

$\odot$ Completed Action Items

View with FEEDBACK

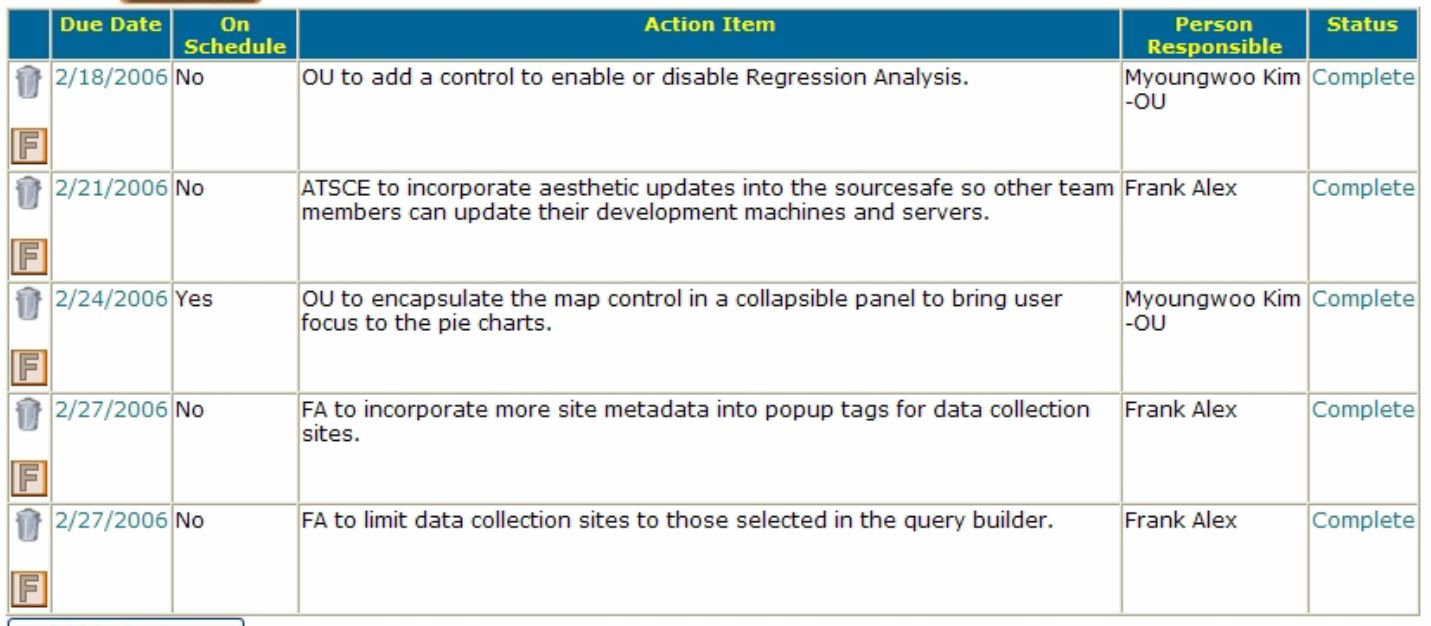

Add Action Item

\section{Meeting Minutes and Memos}

[3] 01-050 meeting agenda and notes 01-29-2003-distributable.pdf 7 conference call 02-01-2006 -minutes.pdf

ㄱ. 01-050 meeting agenda and notes 04-25-2003-distributable.pdf "3. Conference Call Meeting Notes -09 182002 final.pdf

고 01-050 meeting agenda and notes 07-09-2003.pdf 그 Conference Call Meeting Notes 11-20-2002.pdf

01-050 meeting notes 03-05-2003.pdf

ㄱ. Conference Call Meeting Notes-final.pdf

01-050 Ohio Visit ACTION ITEMS 02-05-2003.pdf

Conference Call Notes - 10-14-2003.pdf

ㄹ. 2nd annual project team Meeting Notes.pdf

Upload Files

Adobe Acrobat Reader required to view these files

T4 Get Adobe

Adobe Reader

Figure 14 - Meeting Center 


\section{RESULTS AND DISCUSSION}

The first phase includes data inventory, benchmarking and database population tasks, as well as the development of data management architecture, a web-based retrieval system and an internal QA/QC system. A progress summary for Phase One is shown in Table 4:

Table 4 - Phase One Progress Summary

\begin{tabular}{|l|l|l|l|}
\hline Task \# & Description & $\begin{array}{l}\text { Planned } \\
\text { completed }\end{array}$ & $\begin{array}{l}\text { Actual \% } \\
\text { completed }\end{array}$ \\
\hline 1.1 & Data Inventory/Benchmarking for Database Applications & $100 \%$ & $100 \%$ \\
\hline 1.2 & Develop Data Management System Architecture & $100 \%$ & $100 \%$ \\
\hline 1.3 & Population of Database & $100 \%$ & $100 \%$ \\
\hline 1.4 & Develop Web-based Retrieval System & $100 \%$ & $100 \%$ \\
\hline 1.5 & Develop Internal QA/QC System & $\mathrm{N} / \mathrm{A}$ & $\mathrm{N} / \mathrm{A}$ \\
\hline
\end{tabular}

The second project development phase is currently being finalized. The tasks involved in this phase include the development of a stakeholder-specific website, a publicly accessible website and an online help feature. This phase also includes the development of special analysis tools to provide a graphical representation of the data and a series of performance tests designed to provide the best possible data management solution.

A progress summary for Phase Two is shown in Table 5.

Table 5 - Phase Two Progress Summary

\begin{tabular}{|l|l|l|l|}
\hline Task \# & Description & $\begin{array}{l}\text { Planned } \\
\text { completed }\end{array}$ & $\begin{array}{l}\text { Actual \% } \\
\text { completed }\end{array}$ \\
\hline 2.1 & Develop Stakeholder Website & $100 \%$ & $100 \%$ \\
\hline 2.2 & Develop Public Website & $100 \%$ & $99 \%$ \\
\hline 2.3 & Develop Online Help Feature & $100 \%$ & $90 \%$ \\
\hline 2.4 & Provide Graphical Representation of Data & $100 \%$ & $100 \%$ \\
\hline 2.5 & Performance Test & $100 \%$ & $75 \%$ \\
\hline
\end{tabular}

\section{CONCLUSION}

The development efforts have so far proceeded as expected. Some target milestones were not been met in a timely manner primarily due to delays in acquiring input data from third party sources. This is especially so with the data inventory task, where data reformatting issues were also encountered. Delays have also been an inevitable consequence of the philosophy of the DOE COR and the project team to proceed very carefully and deliberately with the development of the stakeholder website. It is believed that the ultimate success of this project will require a high degree of stakeholder confidence and subsequent participation in the website development process, and that such participation will be greatly enhanced if stakeholders are presented with a relatively "polished" product at the outset. Therefore, the extra programming effort has been dedicated toward developing and refining a limited set of fully-functional graphic and analytical routines 
(e.g., time series analysis and box plots) before fully pursuing a potentially expensive program of stakeholder engagement. The DOE COR has also been actively involved in an on-going evaluation and $\beta$-testing of the developing website and analytical tools, providing critical feedback that has been instrumental in modifications that have made the application more user-friendly and the navigation much more dynamic.

The hurdles encountered, however, have not been insurmountable, as other parts of the project have proceeded as proposed. Since the level of effort associated with the slowed tasks is still the same, the costs to complete this task will not be impacted either negatively or positively. The project is currently proceeding on a no-cost time extension through August 2007. 


\section{REFERENCES}

1. O’Brien, G., Hughes, V., Modeling Support, California Air Resources Board Designing a Data Management System for the Central California Air Quality Studies http://www.arb.ca.gov/airways/Documents/DOCS/AWMACCAQS_Mar2301.pdf

2. Professors Spyros Pandis, Cliff Davidson, and Allen Robinson, Carnegie Mellon University

EPA Supersite - Carnegie Mellon University

http://homer.cheme.cmu.edu

3. Robinson P. Khosah, Ph.D., Advanced Technology Systems, Inc.

Semi-Annual Technical Progress Report

http://www.netl.doe.gov/coalpower/environment/air_q/docs/40456ro6.pdf

4. Karen Magliano, California Air Resources Board; Philip Roth, Envair; Charles Blanchard, Envair; Steven Reynolds, Envair; Steve Ziman, Chevron; Rob DeMandel, Bay Area Air Quality Management District

California Regional $\mathrm{Pm}_{10} / \mathrm{Pm}_{2.5}$ Air Quality Study: Objectives and Associated Data Analysis and Modeling Approaches

http://www.arb.ca.gov/airways/Documents/reports/objectiv.doc

5. Robinson P. Khosah, Ph.D., Charles G. Crawford Advanced Technology Systems, Inc.

Semi-Annual Technical Progress Report \#1

http://www.netl.doe.gov/coalpower/environment/air_q/docs/41476R01.pdf

6. Robinson P. Khosah, Ph.D., Charles G. Crawford Advanced Technology Systems, Inc.

Semi-Annual Technical Progress Report \#2

http://www.netl.doe.gov/coalpower/environment/air_q/docs/41476R02.pdf

7. Robinson P. Khosah, Ph.D., Charles G. Crawford Advanced Technology Systems, Inc.

Semi-Annual Technical Progress Report \#3

http://www.netl.doe.gov/coalpower/environment/air_q/docs/41476R03.pdf

8. Robinson P. Khosah, Ph.D., Charles G. Crawford Advanced Technology Systems, Inc.

Semi-Annual Technical Progress Report \#4

http://www.netl.doe.gov/coalpower/environment/air_q/docs/41476R04.pdf

9. Robinson P. Khosah, Ph.D., Charles G. Crawford Advanced Technology Systems, Inc.

Semi-Annual Technical Progress Report \#5

http://www.netl.doe.gov/coalpower/environment/air q/docs/41476R05.pdf

10. Robinson P. Khosah, Ph.D., Charles G. Crawford Advanced Technology Systems, Inc.

Semi-Annual Technical Progress Report \#6

http://www.netl.doe.gov/coalpower/environment/air_q/docs/41476R06.pdf 


\section{BIBLIOGRAPHY}

Not applicable. 


\section{LIST OF TERMS, ACRONYMS AND ABBREVIATIONS}

Term

Admin Level

ACHD

APM

Application Account

Application

Administrator

Browse Level

Cached Data

CARB

CSV

Data Administrator

Data Submitter

DOE-NETL

Foreign Key

FTP

GIS

GMT Offset

\section{Definition}

Security level indicating the degree of access a specific user possesses to administration utilities and data.

Allegheny County Health Department

Automated Population Module

An application account (Windows 2000). This account is created and edited using Windows 2000.

An individual responsible for managing application performance, user access and newsletter/announcement notification services.

Security level indicating the areas of the application and datasets that a specific user can 'browse' through.

Data retained at the server level to serve frequently polled data. These datasets are cached, or stored, at the server and reduce query loads on the database server, thus increasing overall efficiency and application response time.

\section{California Air Resources Board}

Comma Separated Value

An individual responsible for managing the database housing the PM data, as well as managing all assigned data submission accounts.

Individual user who has permission to submit data for inclusion in the PM database.

US Department of Energy's National Energy Technology Laboratory

A non-negative whole number used to reference a data row in a related table.

File Transfer Protocol.

Geographic Information Systems

Number of hours that, when added to the local time values, provides GMT Time values; e.g. 11:00AM local time, with a GMT offset value of -5 means that the GMT time value for this local time value would be 6:00AM GMT. 
Term

HTTP

Media

Metaflag

Method

NARSTO

NARSTO Metaflag

NOAA

PA-DEP

Parameter

Parameter Identifier

Parameter Property

Primary Key

Parameter Source

QA/QC

QC Status

Read Level

Sample Duration

\section{Definition}

Hypertext Transfer Protocol

Filter used to collect speciation samples.

Localized flagging system specific to a particular submitting authority.

Descriptive text that describes how data was collected.

An acronym for "North American Research Strategy for Tropospheric Ozone." A tri-national, public-private partnership for dealing with multiple features of tropospheric pollution, including ozone and suspended particulate matter.

Standardized flagging system (NARSTO). Each metaflag is mapped to a NARSTO metaflag to provide meaningful results when querying across datasets originating from multiple submitting authorities.

National Oceanic and Atmospheric Administration

Pennsylvania Department of Environmental Protection

A concatenated descriptive definition of what the observation value represents. Components of a valid parameter include: parameter property, parameter identifier, collection principle, and parameter source.

Descriptive text that identifies a chemical property of a parameter.

Descriptive text that identifies a physical property of a parameter.

Unique non-negative whole number used to reference each row in a database table. This is used to identify relationships between related items in related tables.

Originating organization for parameter codes and descriptions.

Quality Assurance / Quality Control

Quality control status code.

Security level indicating the areas of the application and datasets to which a specific user has read access.

Text describing the sample duration that is used to collect a specific sample. This usually applies only to filter data; sample duration of $\mathrm{H} 12$ indicates that the sample in question was taken over a 12-hour period. 
Term

Sample Frequency

SQL

Subscriber

System Account

Systems Administrator

User Account

US EPA

VCard

Write Level

WV-DEP

XML

\section{Definition}

Text describing the sample frequency, or interval, between regular readings; e.g. M15 indicates that a sample is taken every 15 minutes.

\section{Structured Query Language}

Individual user who has elected to receive email notification from pmdata.org.

A Windows 2000 Server account used to administer the network and/or application servers.

An individual responsible for managing the hardware and operating system(s) of the hosting computers and networks. This person ensures that the application and database is available to users and works to correct any connectivity issues that may occur.

Application account established for each user that contains each user's contact data and security profile.

US Environmental Protection Agency

Virtual address card. This is similar to a rolodex entry, containing an address, city, state and zip code. A VCard can link to multiple entities sharing the same physical address. Entries also contain a location's county and country.

Security level indicating the areas of the application and datasets to which a specific user may enter new records or modify existing records.

West Virginia Department of Environmental Protection

Extensible Markup Language 


\section{Appendix I - Comprehensive Data Record Inventory}

\begin{tabular}{|c|c|}
\hline PITTSBURGH SUPERSITE & $1,306,134$ \\
\hline Description & Record Count \\
\hline MET Air Pressure & 68,075 \\
\hline MET Ambient Temperature & 68,075 \\
\hline MET Relative Humidity & 67,991 \\
\hline MET Downwelling UV Radiation & 67,991 \\
\hline MET Broadband Downwelling Solar Hemispheric Radiation & 67,991 \\
\hline MET Sigma Theta-standard deviation of wind direction & 67,991 \\
\hline MET Current Precipitation [Rain Gauge] & 67,991 \\
\hline MET Unit Vecto Mean Wind Direction [Wind direction vane] & 67,991 \\
\hline MET Horizontal Scalar Max Wind Speed [Anemometer--cup] & 67,991 \\
\hline MET Horizontal Scalar Mean Wind Speed [Anemometer--cup] & 67,991 \\
\hline PM2.5 Ionic-SO4 [Automated particulate sulfate monitor] & 61,488 \\
\hline GAS SO2 [Pulsed fluorescence] & 61,488 \\
\hline GAS CO1 [Infrared absorption] & 61,488 \\
\hline GAS Nitric Oxide [Chemiluminescence] & 61,488 \\
\hline PM2.5 I onic-NO3 [Automated particulate nitrate monitor] & 61,488 \\
\hline PM2.5 Particle-Mass [TEOM] & 61,488 \\
\hline GAS NOX [Chemiluminescence] & 61,488 \\
\hline GAS Ozone [Ultraviolet absorption] & 61,488 \\
\hline GAS Total Peroxide [Fluorescence--other] & 9,740 \\
\hline PM2.5 Light Scatter Co-efficient [Optical scattering--integrating nephelometer] & 8,384 \\
\hline MET Instrument Temperature & 8,384 \\
\hline MET Ambient Temperature & 8,384 \\
\hline PM2.5 Ionic-CL [Continuous gas and particle speciation monitor] & 5,508 \\
\hline PM2.5 Ionic-NA [Continuous gas and particle speciation monitor] & 5,508 \\
\hline PM2.5 I onic-NO2 [Continuous gas and particle speciation monitor] & 5,508 \\
\hline PM2.5 Ionic-NO3 [Continuous gas and particle speciation monitor] & 5,508 \\
\hline PM2.5 Ionic-NH4 [Continuous gas and particle speciation monitor] & 5,508 \\
\hline PM2.5 Ionic-SO4 [Continuous gas and particle speciation monitor] & 5,508 \\
\hline MOUDI Mass [Impactor] & 3,555 \\
\hline PM2.5 Element-C [Continuous] & 2,561 \\
\hline PM2.5 Organic-C [Continuous] & 2,561 \\
\hline VOC o-Xylene [Continuous] & 1,297 \\
\hline VOC Toluene [Continuous] & 1,297 \\
\hline VOC Tetrachloroethene [Continuous] & 1,297 \\
\hline VOC t-2-Butene [Continuous] & 1,297 \\
\hline VOC N-Butane [Continuous] & 1,297 \\
\hline VOC c-2-Butene [Continuos] & 1,297 \\
\hline VOC Chloroform [Continuous] & 1,297 \\
\hline
\end{tabular}




\begin{tabular}{|c|c|}
\hline VOC m-Xylene [Continuous] & 1,297 \\
\hline VOC Benzene [Continuous] & 1,297 \\
\hline VOC 1-Propene [Continuous] & 1,297 \\
\hline VOC N-Pentane [Continuous] & 1,297 \\
\hline VOC 2-methoxy-2-methyl-Propane [Continuous] & 1,297 \\
\hline VOC 1-Pentene [Continous] & 1,297 \\
\hline VOC Pentane, 2-Methyl- and Pentane, 3-Methyl- [Continuous] & 1,297 \\
\hline VOC 2-Methyl-1-Butene [Continuos] & 1,297 \\
\hline VOC N-Hexane [Continuous] & 1,297 \\
\hline VOC Ethanol [Continuous] & 1,297 \\
\hline VOC Methanol [Continuous] & 1,297 \\
\hline VOC t-2-Pentene [Continuous] & 1,297 \\
\hline VOC Acetone [Continuous] & 1,297 \\
\hline VOC 1-Propyne [Continuous] & 1,297 \\
\hline VOC 2-Propanol [Continuous] & 1,297 \\
\hline VOC Cyclopentane [Continuos] & 1,297 \\
\hline VOC Isopentane [Continuous] & 1,297 \\
\hline VOC 3-Methyl-1-Butene [Continuous] & 1,297 \\
\hline VOC I sobutane [Continuous] & 1,297 \\
\hline VOC Methyl Ethyl Ketone [Continuous] & 1,297 \\
\hline VOC p-Xylene [Continuous] & 1,297 \\
\hline VOC Ethylbenzene [Continuous] & 1,297 \\
\hline VOC 1-Butene [Continuous] & 1,297 \\
\hline VOC Propane [Continuous] & 1,297 \\
\hline GAS Hydrogen Peroxide [Fluorescence--other] & 1,185 \\
\hline GAS Organic Peroxide [Fluorescence--other] & 1,185 \\
\hline PM2.5 Organic-C [Filter - multiple] & 1,032 \\
\hline VOC Acetaldehyde [Continuous] & 662 \\
\hline VOC 1-Propene, 2-Methyl- & 662 \\
\hline VOC Dimethyl Sulfide [Continuous] & 635 \\
\hline VOC 3-Methylfuran [Continuous] & 635 \\
\hline VOC Butanal [Continuous] & 635 \\
\hline VOC Cyclopentene [Continuous] & 635 \\
\hline VOC Dichloromethane [Continuous] & 635 \\
\hline VOC Acetonitrile [Continuous] & 635 \\
\hline VOC Pentanal [Continuous] & 635 \\
\hline VOC Acetaldehyde [Continuous] & 635 \\
\hline VOC Methacrolein [Continuous] & 635 \\
\hline VOC Methyl Vinyl Ketone [Continuous] & 635 \\
\hline VOC Alpha-Pinene [Continuous] & 635 \\
\hline VOC Isoprene [Continuous] & 635 \\
\hline PM2.5 Organic-C [Single Filter] & 516 \\
\hline PM2.5 Element-C [Single Filter] & 516 \\
\hline
\end{tabular}




\begin{tabular}{|l|r|}
\hline PM2.5 Ionic-NH4 [Filter - multiple] & 504 \\
\hline PM2.5 Ionic-NO3 [Filter - multiple] & 504 \\
\hline PM2.5 Ionic-SO4 [Filter - multiple] & 504 \\
\hline GAS Nitric Acid [Filter - multiple] & 504 \\
\hline GAS Ammonia [Filter - multiple] & 504 \\
\hline PM2.5 Mass [FRM] & 404 \\
\hline PM10 Filter-Mass [Single Filter] & 377 \\
\hline PM2.5 Filter-Mass [Single Filter] & 377 \\
\hline PM2.5 Element-C [Filter+denuder] & 84 \\
\hline PM2.5 Organic-C [Filter+denuder] & 84 \\
\hline CLO Ionic-CL [Cloud/Fog water--active] & 8 \\
\hline CLO Ionic-SO4 [Cloud/Fog water--active] & 8 \\
\hline CLO Ionic-K [Cloud/Fog water--active] & 8 \\
\hline CLO Ionic-CA [Cloud/Fog water--active] & 8 \\
\hline CLO Fog Water-Volume [Cloud/Fog water--active] & 8 \\
\hline CLO Organic-C [Cloud/Fog water--active] & 8 \\
\hline CLO Ionic-NO3 [Cloud/Fog water--active] & 8 \\
\hline CLO Ionic-NH4 [Cloud/fog water--active] & 8 \\
\hline CLO Fog Water-PH [Cloud/Fog water--active] & 8 \\
\hline CLO Total Dissolved Organic-C [Cloud/Fog water--active] \\
\hline CLO Ionic-NA [Cloud/fog water--active] \\
\hline CLO Ionic-MG [Cloud/Fog water--active] \\
\hline CLO Ionic-NITRITE [Cloud/Fog water--active] \\
\hline
\end{tabular}

\begin{tabular}{|l|l|}
\hline LAWRENCEVI LLE PRI MARY & $\mathbf{2 5 8 , 6 4 1}$ \\
\hline Description & Record Count \\
\hline PM10 Particle-Concentration [TEOM] & 90,253 \\
\hline PM2.5 Particle-Concentration [TEOM] & 75,747 \\
\hline PM2.5 Particle-Mass [TEOM] & 24,672 \\
\hline PM10 Particle-Mass [TEOM] & 21,779 \\
\hline PM2.5 Flow-Vol [Not assigned] & 3,180 \\
\hline PM2.5 Element-AG [Filter+denuder] & 2,389 \\
\hline PM2.5 Filter-Mass [Filter+denuder] & 1,831 \\
\hline PM10 Flow-Vol [Other] & 1,730 \\
\hline PM2.5 Element-AS [Filter+denuder] & 1,347 \\
\hline PM2.5 Element-AL [Filter+denuder] & 1,347 \\
\hline PM2.5 Ionic-CHL [Filter+denuder] & 1,329 \\
\hline TSP Flow-Vol [Not assigned] & 1,080 \\
\hline PM2.5 Element-AU [Filter+denuder] & 946 \\
\hline PM2.5 Element-IN [Filter+denuder] & 946 \\
\hline PM2.5 Element-HG [Filter+denuder] & 898 \\
\hline PM2.5 Element-CR [Filter+denuder] & 898 \\
\hline
\end{tabular}




\begin{tabular}{|c|c|}
\hline PM2.5 Element-BA [Filter+denuder] & 898 \\
\hline PM2.5 Element-CA [Filter+denuder] & 898 \\
\hline PM2.5 Element-BR [Filter+denuder] & 898 \\
\hline PM2.5 Element-CU [Filter+denuder] & 898 \\
\hline PM2.5 Element-CD [Filter+denuder] & 898 \\
\hline PM2.5 Element-FE [Filter+denuder] & 898 \\
\hline PM2.5 Element-CO [Filter+denuder] & 898 \\
\hline PM2.5 Element-GA [Filter+denuder] & 898 \\
\hline PM2.5 Element-C [Filter+denuder] & 886 \\
\hline PM10 Filter-Mass [Filter+denuder] & 758 \\
\hline TSP Element-NO3 [Filter--multiple] & 524 \\
\hline TSP Element-NO3 [Denuder--cylinder+filter(s)] & 524 \\
\hline PM2.5 Element-RB [Filter+denuder] & 449 \\
\hline PM2.5 Element-SN [Filter+denuder] & 449 \\
\hline PM2.5 Element-MO [Filter+denuder] & 449 \\
\hline PM2.5 Element-V [Filter+denuder] & 449 \\
\hline PM2.5 Element-TL [Filter+denuder] & 449 \\
\hline PM2.5 Element-MG [Filter+denuder] & 449 \\
\hline PM2.5 Element-ZR [Filter+denuder] & 449 \\
\hline PM2.5 Element-SI [Filter+denuder] & 449 \\
\hline PM2.5 Element-U [Filter+denuder] & 449 \\
\hline PM2.5 Element-TI [Filter+denuder] & 449 \\
\hline PM2.5 Element-LA [Filter+denuder] & 449 \\
\hline PM2.5 Element-ZN [Filter+denuder] & 449 \\
\hline PM2.5 Element-SB [Filter+denuder] & 449 \\
\hline PM2.5 Element-S [Filter+denuder] & 449 \\
\hline PM2.5 Element-PB [Filter+denuder] & 449 \\
\hline PM2.5 Element-NA [Filter+denuder] & 449 \\
\hline PM2.5 Element-P [Filter+denuder] & 449 \\
\hline PM2.5 Element-SE [Filter+denuder] & 449 \\
\hline PM2.5 Element-MN [Filter+denuder] & 449 \\
\hline PM2.5 Element-PD [Filter+denuder] & 449 \\
\hline PM2.5 Element-Y [Filter+denuder] & 449 \\
\hline PM2.5 Element-NI [Filter+denuder] & 449 \\
\hline PM2.5 Element-K [Filter+denuder] & 449 \\
\hline PM2.5 Element-SR [Filter+denuder] & 449 \\
\hline PM2.5 Organic-TOC [Filter+denuder] & 443 \\
\hline PM2.5 Element-SO4 [Filter+denuder] & 443 \\
\hline PM2.5 Ionic-NA [Filter+denuder] & 443 \\
\hline PM2.5 Organic-C [Filter+denuder] & 443 \\
\hline PM2.5 Element-NO3 [Filter+denuder] & 443 \\
\hline PM2.5 Element-NH4 [Filter+denuder] & 443 \\
\hline PM2.5 Ionic-K [Filter+denuder] & 443 \\
\hline
\end{tabular}




\begin{tabular}{|c|c|}
\hline PM2.5 Acid-H2SO4 [Filter+denuder] & 401 \\
\hline PM2.5 Gas-TOC [Filter+denuder] & 401 \\
\hline PM2.5 Gas-C [Filter+denuder] & 401 \\
\hline TSP Element-NH4 [Filter--multiple] & 262 \\
\hline PM10 Element-AG [Filter+denuder] & 159 \\
\hline PM10 Ionic-CHL [Filter+denuder] & 123 \\
\hline PM10 Element-AS [Filter+denuder] & 123 \\
\hline PM10 Element-AL [Filter+denuder] & 123 \\
\hline PM2.5 Element-CL [Filter+denuder] & 96 \\
\hline PM10 Element-FE [Filter+denuder] & 82 \\
\hline PM10 Element-BR [Filter+denuder] & 82 \\
\hline PM10 Element-CD [Filter+denuder] & 82 \\
\hline PM10 Element-CR [Filter+denuder] & 82 \\
\hline PM10 Element-IN [Filter+denuder] & 82 \\
\hline PM10 Element-CU [Filter+denuder] & 82 \\
\hline PM10 Element-CO [Filter+denuder] & 82 \\
\hline PM10 Element-GA [Filter+denuder] & 82 \\
\hline PM10 Element-AU [Filter+denuder] & 82 \\
\hline PM10 Element-CA [Filter+denuder] & 82 \\
\hline PM10 Element-HG [Filter+denuder] & 82 \\
\hline PM10 Element-BA [Filter+denuder] & 82 \\
\hline PM10 Element-C [Filter+denuder] & 82 \\
\hline PM2.5 Acid-SAEC [Filter+denuder] & 49 \\
\hline PM10 Element-NI [Filter+denuder] & 41 \\
\hline PM10 Element-K [Filter+denuder] & 41 \\
\hline PM10 Element-NO3 [Filter+denuder] & 41 \\
\hline PM10 Element-ZN [Filter+denuder] & 41 \\
\hline PM10 Element-LA [Filter+denuder] & 41 \\
\hline PM10 Element-SB [Filter+denuder] & 41 \\
\hline PM10 Element-PD [Filter+denuder] & 41 \\
\hline PM10 I onic-NA [Filter+denuder] & 41 \\
\hline PM10 Element-MN [Filter+denuder] & 41 \\
\hline PM10 Element-U [Filter+denuder] & 41 \\
\hline PM10 Element-TI [Filter+denuder] & 41 \\
\hline PM10 Element-SI [Filter+denuder] & 41 \\
\hline PM10 Acid-H2SO4 [Filter+denuder] & 41 \\
\hline PM10 Element-SO4 [Filter+denuder] & 41 \\
\hline PM10 Element-Y [Filter+denuder] & 41 \\
\hline PM10 Organic-TOC [Filter+denuder] & 41 \\
\hline PM10 Element-SR [Filter+denuder] & 41 \\
\hline PM10 Element-NA [Filter+denuder] & 41 \\
\hline PM10 Element-MO [Filter+denuder] & 41 \\
\hline PM10 Gas-C [Filter+denuder] & 41 \\
\hline
\end{tabular}




\begin{tabular}{|l|l|}
\hline PM10 Element-S [Filter+denuder] & 41 \\
\hline PM10 Element-V [Filter+denuder] & 41 \\
\hline PM10 Element-P [Filter+denuder] & 41 \\
\hline PM10 Element-TL [Filter+denuder] & 41 \\
\hline PM10 Ionic-K [Filter+denuder] & 41 \\
\hline PM10 Element-SN [Filter+denuder] & 41 \\
\hline PM10 Element-RB [Filter+denuder] & 41 \\
\hline PM10 Gas-TOC [Filter+denuder] & 41 \\
\hline PM10 Element-NH4 [Filter+denuder] & 41 \\
\hline PM10 Element-MG [Filter+denuder] & 41 \\
\hline PM10 Organic-C [Filter+denuder] & 41 \\
\hline PM10 Element-SE [Filter+denuder] & 41 \\
\hline
\end{tabular}

\section{HOLBROOK PRI MARY}

Description

PM2.5 Particle-Concentration [TEOM]

PM2.5 Particle-Mass [TEOM]

PM2.5 Flow-Vol [Not assigned]

PM2.5 Element-AG [Filter+denuder]

PM10 Flow-Vol [Other]

PM2.5 Filter-Mass [Filter+denuder]

\begin{tabular}{|r|r|}
\hline Record Count & $\mathbf{1 3 4 , 0 6 6}$ \\
\hline 88,903 \\
\hline 32,122 \\
\hline 1,028 \\
\hline 740 \\
\hline 638 \\
\hline 634 \\
\hline
\end{tabular}

MORGANTOWN SATELITE

Description

Record Count

PM2.5 Flow-Vol [Not assigned]

PM2.5 Filter-Mass [Filter+denuder] 